\title{
PREVALENCE OF ANATOMIC VARIATIONS IN CHRONIC RHINOSINUSITIS.
}

Shrikrishna B. H, Jyothi A. C, Sanjay G, Sandeep Samson G.

1. Associate Professor. Department of ENT \& Head Neck Surgery, Navodaya Medical College Hospital \& Research Centre, Raichur, Karnataka.

2. Associate Professor. Department of ENT \& Head Neck Surgery, Navodaya Medical College Hospital \& Research Centre, Raichur, Karnataka.

3. Senior Resident. Department of ENT \& Head Neck Surgery, Navodaya Medical College Hospital \& Research Centre, Raichur, Karnataka.

4. Senior Resident. Department of ENT \& Head Neck Surgery, Navodaya Medical College Hospital \& Research Centre, Raichur, Karnataka.

\section{CORRESPONDING AUTHOR:}

Dr. Shrikrishna B. H,

Associate Professor,

Department of ENT and Head-Neck Surgery,

Navodaya Medical College Hospital and Research Centre,

Mantralayam Road, Raichur,

Karnataka (India) - 584103.

E-mail: drshrikrishna@gmail.com

Ph: 00919880260238

ABSTRACT: OBJECTIVE: To determine the prevalence of anatomic variations in patients suffering from chronic rhinosinusitis (CRS) and to compare them with normal population. DESIGN: This is a case control study. A prospective study of anatomic variations was done on 100 computed tomography (CT) scans of patients with chronic rhinosinusitis. Prevalence of anatomic variations in control group was assessed by studying $100 \mathrm{CT}$ scans of non- CRS patients. RESULTS: Even though proportion of concha bullosa was more among chronic rhinosinusitis patients compared to normal individuals, it was statistically not significant. There was no significant difference in the prevalence of paradoxical middle turbinate, retroverted uncinate process, overpneumatized ethmoid bulla and septal deviation in chronic rhinosinusitis patients compared to normal individuals. There was significantly lesser proportion of individuals having haller cells and agger nasi cells in chronic rhinosinusitis compared to normal individuals. CONCLUSION: There is no significant prevalence of anatomic variations in osteomeatal unit in patients with chronic rhinosinusitis. The anatomic variations may predispose to pathological changes only if they are bigger in size. More detailed studies are recommended in this regard as a good knowledge of complex anatomy of the paranasal sinuses is essential to understand chronic rhinosinusitis and to plan its treatment.

KEY WORDS: rhinosinusitis; tomography; anatomic variation; concha; maxillary sinus; ethmoid sinus.

INTRODUCTION: The European Academy of Allergology and Clinical Immunology (EAACI) defines chronic rhinosinusitis (CRS) as nasal congestion or blockage lasting for more than 12 weeks accompanied by one of the following three sets of symptoms: facial pain or pressure; purulent nasal discharge or post-nasal drip; or hyposmia ${ }^{1}$. Untreated chronic sinusitis can result in severe complications such as orbital cellulitis, osteomyelitis, subdural empyema, frontal lobe abscess, cavernous sinus thrombosis and death ${ }^{2}$. Identifying the predisposing factors for chronic 
sinusitis is therefore very important. Particularly, paranasal anatomical variants have been investigated by several studies, and concha bullosa has been shown to be a common predisposing factor for sinusitis ${ }^{3}$. However, in some studies no relationship was found between the anatomic variants and sinus diseases.

During fetal development, the paranasal sinuses originate as invagination of the nasal mucosa into the lateral nasal wall, frontal, ethmoid, maxilla and the sphenoid bones. This unique development explains the enormous amount of anatomical variation ${ }^{4}$. In regard with the abovementioned differences in the reports, and the prevalence of chronic sinusitis and its complications, we carried out this study to determine the prevalence of anatomic variations in patients suffering from chronic rhinosinusitis (CRS) and to compare them with normal population. Computed tomography (CT) is an excellent means of providing anatomical information of this region, assessing disease extent, assisting endoscopic evaluation and guiding treatment.

OBJECTIVE: Our study aimed to determine the prevalence of anatomic variations_in patients suffering from chronic rhinosinusitis (CRS) and to compare them with normal population.

MATERIALS AND METHODS: This was a prospective case control study; conducted over a period of 1 and half year from 1st June 2011 to 31st December 2012.This study was carried out at the Department of ENT and Head Neck Surgery, Navodaya Medical College, Raichur. One hundred patients with clinical features of chronic rhinosinusitis not responding to medical management were subjected to Computed Tomography (CT) of the paranasal sinus region. The CT scans were selected depending on the following inclusion/exclusion criteria:

Inclusion Criteria:

1. Adult patients

2. Irrespective of socio-economic status.

3. Clinical diagnosis of Chronic Rhinosinusitis.

4. CT scan with $4 \mathrm{~mm}$ or more mucosal thickening in any of the paranasal sinus. Exclusion Criteria:

1. History of previous sinus surgery.

2. History of benign tumours of sinonasal mucosa.

3. History of facial trauma.

The control group was taken from patients who had undergone CT scan of the paranasal sinus region for a reason other than chronic rhinosinusitis for example, trauma, evaluation of headache and were not having any evidence of chronic rhinosinusitis.

All CT scans were obtained with GE Pro-Speed Plus 4 Slice Multidetector CT machine. After obtaining the scout projection, the area of scanning was defined to include the region from roof of frontal sinus up to the hard palate. Axial sections were performed with the patient in supine position and the plane of data acquisition parallel to hard palate. The sections were taken with slice thickness of $5 \mathrm{~mm}$. Coronal sections were performed with the patients in prone position with extended neck and the plane perpendicular to axial plane.

In both the groups of CT scans, presence of any anatomic variations was documented. The anatomic variations studied include concha bullosa, paradoxical middle turbinate, retroverted uncinate process, overpneumatized ethmoid bulla, haller cells, agger nasi cells and septal deviation. The collected data was subjected to statistical analysis. Software used for 
analysis is Epi Info version 6 and the test applied is Chi-square test (Fisher's exact test whenever an expected cell value is $<5$ ).

ETHICAL CONSIDERATIONS: The study got clearance by the Institutional Ethical Committee before its commencement. Also, a written informed consent was taken from all the patients before participating in the study.

RESULTS: One hundred CT scan films in case group and 100 CT scan films in control group were studied. The average age in the case group was 36.4 years (ranged between 18 and 58 years). There were 63 males (63\%) and 37 females (37\%) in the group. The average age in the control group was 29.6 years (ranged between 19 and 46 years). There were 58 males (58\%) and 42 females (42\%) in the group.

Concha bullosa was the most common anatomic variation found in our study. It was observed in 38 cases of chronic rhinosinusitis (38\%) and in 29 cases of non-CRS group (29\%) [Table no 1]. Even though proportion of concha bullosa was more among chronic rhinosinusitis patients compared to normal individuals it was statistically not significant ( $\mathrm{p}=0.17)$. The nasal septal deviation was the next common variation. It was observed in 30 cases of chronic rhinosinusitis (30\%) and in 26 cases of non-CRS group (26\%) ( $\mathrm{p}=0.528)$. The agger nasi cells were observed in 6 cases of chronic rhinosinusitis (6\%) and in 47 cases of non-CRS group $(47 \%)(p=0.00)$. Haller cells were observed in 11 cases of chronic rhinosinusitis $(11 \%)$ and in 27 cases of non-CRS group (27\%) ( $\mathrm{p}=0.003)$. Paradoxical middle turbinate was observed in 5 cases of chronic rhinosinusitis (5\%) and in 9 cases of non-CRS group (9\%) (p=0.26). Overpneumatized ethmoid bulla was observed in 4 cases of chronic rhinosinusitis (4\%) and in 5 cases of non-CRS group (5\%) ( $\mathrm{p}=1.00)$. Retroverted uncinate process was observed in 1 case of chronic rhinosinusitis (1\%) and in 2 cases of non-CRS group $(2 \%)(\mathrm{p}=1.00)$. There was no significant difference in the prevalence of paradoxical middle turbinate, retroverted uncinate process, overpneumatized ethmoid bulla and septal deviation in chronic rhinosinusitis patients compared to normal individuals. There was significantly lesser proportion of individuals having haller cells and agger nasi cells in chronic rhinosinusitis compared to normal individuals.

DISCUSSION: Osteomeatal complex has been defined by various authors in different ways. Zinreich 5,6 includes maxillary sinus ostium and ethmoidal infundibulum and the normal aerated channels which provide air flow and mucociliary clearance of the maxillary, ethmoidal, frontal and sphenoidal sinuses as part of the complex. However, OMC is often referred to the area encompassed by: (a) The ostium of maxillary sinus, the ostia of anterior ethmoidal air cells, the frontonasal duct (frontal recess), the ethmoidal infundibulum, and the middle meatus and (b) The sphenoethmoidal recess and the superior meatus ${ }^{7}$. The (a) and (b) have also been referred to as the anterior and posterior osteomeatal units respectively8.

Stammberger ${ }^{9}$ and Stammberger et al ${ }^{10}$ proposed that stenosis of the osteomeatal complex, from either the anatomical configuration or hypertrophied mucosa, can cause obstruction and stagnation of secretions that may become infected or perpetuate infection.

The middle meatus and lateral nasal wall are subject to wide normal variations that must be distinguished from pathologic changes. These variations may, themselves, be the underlying cause of recurrent sinus disease. However, there is a lack of consensus among investigators with respect to the prevalence and clinical significance of these variations, as they have been encountered with similar frequency in patients being scanned for sinus-related 
problems, as well as those undergoing evaluation for non-sinus-related problems ${ }^{11}$. The more common variations can be divided into four groups, depending on the structures involved: middle turbinate bone, uncinate process, ethmoidal bulla and nasal septum.

Middle Turbinate Variations: Concha bullosa.-The middle turbinate bone is usually a thin plate of bone. When this plate becomes pneumatized by extension of the anterior $(55 \%)$ or posterior (45\%) ethmoidal air cells, the air cell created is referred to as concha bullosa ${ }^{11}$ (Figures 1 and 2). The reported prevalence of concha bullosa ranges from $4 \%$ to $80 \%$, depending on criteria for pneumatization and differences in study populations. "True" concha bullosa (pneumatization of both the vertical lamellar and inferior bulbous portions) is reported in $4-15.7 \%$ of the population ${ }^{11}$, 12 . If the definition is broadened to include any degree of middle turbinate pneumatization, the prevalence increases to $34 \%{ }^{13}$. The highest prevalence $(80 \%)$ is found in patients with chronic sinusitis ${ }^{14}$. For this reason, some suggest that concha bullosa may be a contributing factor in the pathogenesis of sinus inflammatory disease, although others do not share this view ${ }^{11}$. Stammberger and Wolf ${ }^{15}$ and Lidov and Som ${ }^{16}$ reported that concha bullosa can, when sufficiently large, produce signs and symptoms by encroaching on the infundibulum.

Paradoxically curved middle turbinate bone.-Normally, the convexity of the middle turbinate bone is directed medially, toward the nasal septum. When paradoxically curved, the convexity is directed laterally, toward the lateral sinus wall (Figure 3). A $26.1 \%$ prevalence of paradoxically curved middle turbinates has been reported ${ }^{11}$. Although no studies relate this variation to sinus disease, it is a presumed etiologic factor because of the deformity and obstruction or alteration of nasal passage air flow dynamics, especially when associated with other variations ${ }^{15}$.

Uncinate Variations: Deviation of the uncinate tip.-The superior aspect of the uncinate tip may deviate laterally, medially, or anteriorly out of the meatus, appearing as a second middle turbinate bone ${ }^{15}$. When deviated medially, it comes into contact with and compromises the middle meatus. When deviated laterally, it may encroach on the hiatus semilunaris and infundibulum, impeding drainage and ventilation of the anterior ethmoidal, frontal, and maxillary sinuses (Figure 4). The exact prevalence of these variations and their relation to sinus disease has not been determined.

Pneumatized uncinate tip (uncinate bulla).-The exact mechanism by which uncinate pneumatization occurs is not known. It has been proposed that this process is due to growth of agger nasi cells into the most antero-superior region of the uncinate process ${ }^{11}$. Studies reveal a prevalence of $0.4-2.5 \%{ }^{11}$. This variation has been implicated in narrowing of the infundibulum, producing impaired sinus ventilation ${ }^{5}$.

Ethmoidal Variations: Haller cells-According to Kennedy and Zinreich ${ }^{17}$, Haller cells, ethmoidal air cells that project inferiorly to the ethmoidal bulla into the floor of the orbit in the region of the maxillary sinus ostium, are encountered in $10 \%$ of the population (Figure 5). However, Bolger et al. ${ }^{11}$ defined Haller cells as any air cells located beneath the ethmoidal bulla, lamina papyracea, or orbital floor. Using this criterion, they reported a prevalence of $45 \%$. Although they found no significant difference in the prevalence of Haller cells between patients scanned for chronic sinus disease and patients scanned for non-sinus reasons. Stammberger and Wolf ${ }^{15}$ 
consider the presence of these cells as another predisposing factor for recurrent maxillary sinusitis.

Large ethmoidal bulla.-The ethmoidal bulla can be so extensively pneumatized that it completely fills the sinus of the middle turbinate bone (Figure 6). Stammberger and Wolf 15 reported that an enlarged ethmoidal bulla may contribute to sinus disease by obstructing the infundibulum or middle meatus or by being primarily diseased and filled with pus, cysts, or polyps. The exact prevalence of an enlarged ethmoidal bulla is not known.

Agger nasi cells.-Agger nasi cells, the most constant ethmoidal air cells, lie below the frontal sinus, inferolateral to the lacrimal sinus, and represent pneumatization of the lacrimal bone by extension of the anterior ethmoidal cells ${ }^{12}$. They are located anterior and superior to the insertion of the middle turbinate bone, along the lateral nasal wall ${ }^{15}$ (Figure 7). In anatomic dissection, the prevalence of the agger nasi cell varies from $10 \%^{18}$ to $89 \%^{19}$. Because of their location near the lacrimal sac, involvement of these cells by sinus disease can lead to ocular symptoms. These cells may provide access to the frontal sinus and recess during endoscopy.

Nasal Septum Variations: Nasal septal deviation.-Normally, the structures that make up the nasal septum are aligned to form a straight wall, extending from the cribriform plate superiorly to the hard palate inferiorly. At the junction of the nasal cartilage and vomer, acute bowing and deviation of the septum occur in $20 \%$ of the population ${ }^{20}$. When severe, the deviated septum may compress the middle turbinate bone laterally, narrowing the middle meatus and causing obstruction, secondary inflammation, and infection (Figure 8). When it is associated with swollen membranes, there is additional obstruction to the normal flow of mucus from the sinuses.

Taking into account the normal anatomy of the paranasal sinuses and the osteomeatal unit (i.e. middle meatus, frontal recess and infundibulum), any anatomic abnormality that impedes sinus drainage can potentially cause (chronic) sinus inflammation. Among the anatomic variants, concha bullosa (especially the larger ones), and giant ethmoidal bulla occur in the vicinity of maxillary sinus infundibulum, and agger nasi cells are close to the frontal sinus recess. Therefore, they can compress these outlets ${ }^{21}$. It can be postulated that concha bullosa compresses semilunaris hiatus that is in continuity with maxillary sinus infundibulum, and the mucosal linings of these parts come into contact this sets the stage for mucosal inflammation, which persist as long as the anatomic abnormality is present, causing chronicity 22 .

In a study by Scribno, 59\% of their patients with chronic sinusitis had concha bullosa and $5 \%$ of them had large ethmoidal bulla. The remarkable difference between the prevalence of these variants among their patients as compared with the normal population lead to the conclusion that these anatomic changes probably increase the risk of sinus inflammatory diseases by bringing the mucosal lining of the osteomeatal unit in contact with the mucosal lining of the paranasal sinuses ${ }^{23}$. Also in a Swiss study, S-Nadas reported that $35 \%$ of 151 patients with chronic sinusitis had middle turbinate concha bullosa, and after resecting the anterior third of the pneumatized turbinate, $80 \%$ of the patients showed improvement in their symptoms ${ }^{24}$. Also another study by Lom on 100 patients with signs and symptoms of chronic sinusitis, spiral CT scan of the paranasal sinuses yielded 47 cases of concha bullosa and a significant relationship between this finding and chronic sinusitis was observed ${ }^{25}$. Moreover, Massegur reported 4 cases of concha bullosa with chronic sinusitis who underwent endoscopic operation on the middle turbinate, and all the 4 patients were relieved of their symptoms ${ }^{26}$. There are other studies indicating the role and association of concha bullosa in chronic 
sinusitis $^{27-29}$. In our study, even though proportion of concha bullosa was more among chronic rhinosinusitis patients compared to normal individuals it was statistically not significant $(\mathrm{p}=0.17)$.

In our study, there was no significant difference in the prevalence of paradoxical middle turbinate, retroverted uncinate process, overpneumatized ethmoid bulla and septal deviation in chronic rhinosinusitis patients compared to normal individuals. Moreover, there was significantly lesser proportion of individuals having haller cells and agger nasi cells in chronic rhinosinusitis compared to normal individuals. We assume that the explanation for this may be that, in our study, the size of the anatomic variations was not large enough to exert mass effect on the osteomeatal complex to lead to block in mucosal drainage. For the haller cells, normally we do not expect serious pressure effect or a higher prevalence of chronic sinusitis, since they occur away from the osteomeatal unit. In similar studies by Tatli et.al and Unlu et.al, no relationship was found between the anatomic abnormalities and chronic sinusitis ${ }^{30,31}$.

We can conclude that no important relationship exists among different anatomical variants of paranasal sinuses and chronic rhinosinusitis. An anatomic variant may cause compression of the osteomeatal unit if it is really large due to mass effect. However, the way we had selected our control group, may have brought some degrees of selection bias into our study. It would be better to select the control group from clinics other than ENT clinics. This form of bias may shift the study results toward the null hypothesis (i.e. no difference between the study groups). A long term study involving more sample amount is required to know more about this crucial knowledge.

CONCLUSION: There is no significant prevalence of anatomic variations in osteomeatal unit in patients with chronic rhinosinusitis. The anatomic variations may predispose to pathological changes only if they are bigger in size. More detailed studies are recommended in this regard as a good knowledge of complex anatomy of the paranasal sinuses is essential to understand chronic rhinosinusitis and to plan its treatment.

\section{REFERENCES:}

1. Fokkens W et al. Allergy.2005; 60: 583-601.

2. Valvassori GE, Mafee MF. Imaging of the head \& neck. Gerog Thieme 1995; 248-329.

3. Lioyd G. The sinuses In: Sutton D. Whitehouse RW. Textbook of Radiology and imaging. 6th ed. London: Churchill Livingstone 1998; 2: 1294-1307.

4. Amit N D Dwivedi, Kapil Kumar Singh. CT of the paranasal sinuses: normal anatomy, variants and pathology. Journal of Optoelectronics and Biomedical Materials OctoberDecember 2010; 2(4): 281 - 289.

5. Zinreich SJ, Kennedy DW, Rosenbaum AE, Gayler BW, Kumar AJ, Stammberger H. Paranasal sinuses: CT imaging requirements for endoscopic surgery. Radiology 1987; 163: 769-775.

6. Zinreich SJ, Abidin M, Kennedy DW. Cross-sectional imaging of the nasal cavity and paranasal sinuses. Oper Techniq Otolaryngol Head Neck Surg 1990; 2: 94-98.

7. Mafee MF, Chow JM, Meyers R. Functional endoscopic sinus surgery: Anatomy, CT Screening, indications, and complications. American Journal of Radiology 1993; 160: 735-744.

8. Nayak S. Radiologic anatomy of the paranasal sinuses. Seminars in Ultrasound, CT and MRI 1999; 20: 354-378. 
9. Stammberger H. Secretion transport. In: Functional endoscopic sinus surgery. Philadelphia: BC Decker, 1991: 17-46.

10. Kopp W, Stammberger H, Fotter R. Special radiologic image of the paranasal sinuses. Eur J Radiol 1988; 8:152-156.

11. Bolger WE, Butzin CA, Parsons DS. Paranasal sinus bony anatomic variations and mucosal abnormalities: CT analysis for endoscopic sinus surgery. Laryngoscope 1991; 101:56-64.

12. Ritter FR. The paranasal sinuses: anatomy and surgical technique. St. Louis: Mosby, 1973:24-36.

13. Zinreich Si, Mattox DE, Kennedy DW, Chisholm HL, Diffley DM, Rosenbaum AE. Concha bullosa: CT evaluation. J Comput Assist Tomogr 1988; 12: 778-784.

14. Goldman JL. The principles and practice of rhinology: a text on the diseases and surgery of the nose and paranasal sinuses. New York: Wiley, 1987:405.

15. Stammberger H, Wolf G. Headaches and sinus disease: the endoscopic approach. Ann Otol Rhinol Laryngol Suppl 1988; 97[134]:3-23.

16. Lidov M, Som PM. Inflammatory disease involving a concha bullosa (enlarged pneumatized middle nasal turbinate): MR and CT appearance. AJNR i990; 1 1:999-1001.

17. Kennedy DW, Zinreich SJ. Functional endoscopic approach to inflammatory sinus disease: current perspectives and technique modifications. Am J Rhinol 1988;2:89-96

18. Schaefer SD, Manning 5, Close LG. Endoscopic paranasal sinus surgery: indications and considerations. Laryngoscope 1989; 99: 1-5.

19. Van Alyea OE. Ethmoid labyrinth: anatomic study, with consideration of the clinical significance of its structural characteristics. Arch Otolaryngol Head Neck Surg 1939; 29:881-901.

20. Blaugrund SM. The nasal septum and concha bullosa. Otolaryngol Clin North Am 1989; 22:291-306.

21. Cummings C W. Otolaryngol Head Neck Surgery. Vol 2. 3rd ed. Toronto: Mosby, 1993; 1059 - 1117.

22. Ameri, A. Eslambolchi, H. Bakhshandeh. Anatomic Variants of Paranasal Sinuses and Chronic Sinusitis. Iran. J. Radiol. June 2005; 2(3, 4):121-124.

23. Scribano E, Ascenit G. The role of osteomeatal unit anatomic variations in inflammatory disease of the maxillary sinuses. Eur J Radiol.1997; 24(3): 124 - 127.

24. Pochon N. Incidence and surgery of concha bullosa in chronic rhinosinusitis. Rhinology 1994; 32 (1): 11-14.

25. Lom WW, Laing EY. The etiological role of concha bullosa in chronic sinusitis. Eur Radiol. 1996; 6(4): 550 - 552.

26. Massegur H, Sdema JM. The middle turbinate as the cause of sinusal pathology. Acta Otorhinolaryngol - ESP. 1995; 16(1): 27-29.

27. Nadas S, Duvosini B, Landry N. Concha Bullosa: frequency and appearances on Ct and correlations with sinus disease in 308 patients with chronic sinusitis. J Head Neck Radiol. 1995; 234- 237.

28. CoLoun KH, Waggenspack GA. CT evaluation of paranasal sinuses in symptomatic and asymptomatic populations. 1991; 104 (4):480 -483.

29. Webutsin B, Butsin CA, Parson DS. Paranasal sinus bony anatomic variations and mucosal abnormalities. CT analysis for endoscopic sinus surgery. 1991; 101: 56 - 64. 
30. Tatli MM, San I. Paranasal sinus computed tomographic findings of patients with chronic cough. International Journal of Otorhinolaryngology.2001; 60 (3): 213-21 7.

31. Unlu HH, Akyar S, Caylan R. Concha bullosa. J Otolaryngol. 1994; 23 (1): 23-27.

Table no. 1: bony anatomic variations among crs (chronic rhinosinusitis) and normal population.

\begin{tabular}{|l|c|c|c|c|}
\hline ANATOMICAL VARIATION & $\begin{array}{c}\text { CHRONIC } \\
\text { RHINOSINUSITIS } \\
(\mathbf{n = 1 0 0 )}\end{array}$ & $\begin{array}{c}\text { NORMAL } \\
(\mathbf{n = 1 0 0})\end{array}$ & $\begin{array}{c}\text { TOTAL } \\
(\mathbf{n = 2 0 0})\end{array}$ & p VALUE \\
\hline CONCHA BULLOSA & 38 & 29 & 67 & 0.17 \\
\hline PARADOXICAL MIDDLE TURBINATE & 5 & 9 & 14 & 0.26 \\
\hline RETROVERTED UNCINATE PROCESS & 1 & 2 & 3 & $1.00^{*}$ \\
\hline $\begin{array}{l}\text { OVERPNEUMATIZED ETHMOID } \\
\text { BULLA }\end{array}$ & 4 & 5 & 9 & $1.00^{*}$ \\
\hline HALLER CELLS & 11 & 27 & 38 & $0.003(\mathrm{~S})$ \\
\hline AGGER NASI CELLS & 6 & 47 & 53 & $0.00(\mathrm{~S})$ \\
\hline SEPTAL DEVIATION & 30 & 26 & 56 & 0.528 \\
\hline
\end{tabular}

* Fisher's exact test $\quad \mathrm{S}=$ significant.

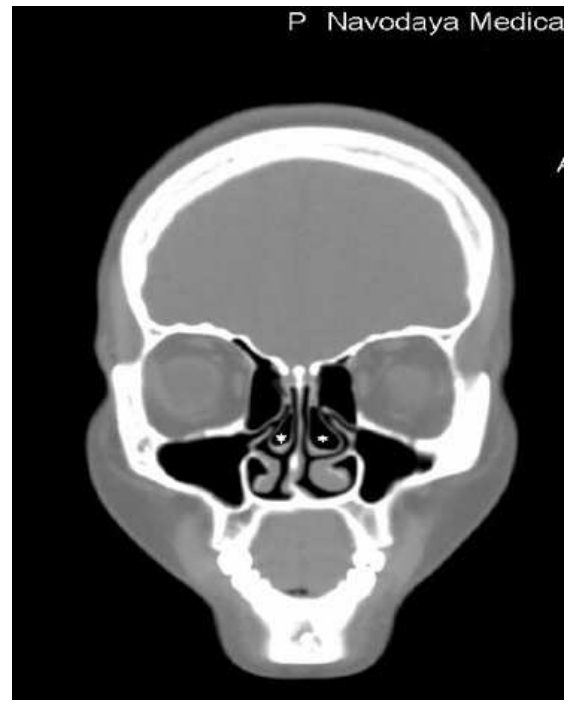

Figure 1: bilateral bulbous concha bullosa (asterix) in a subject of control (normal) group.

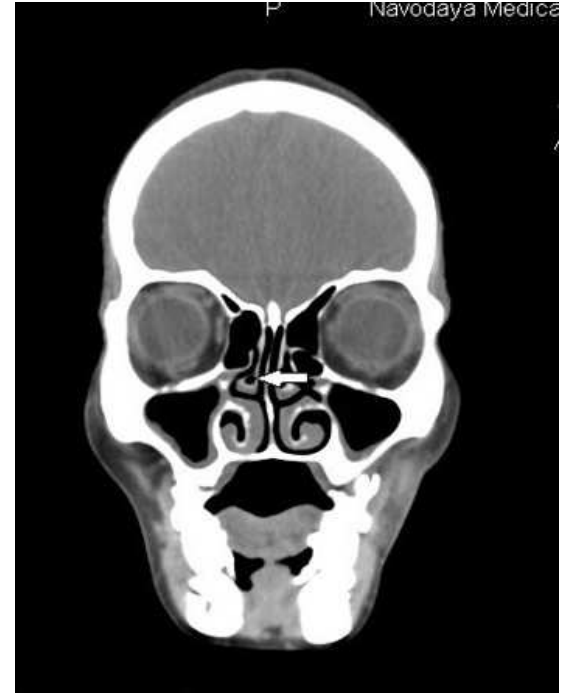

Figure 2: right sided bulbous concha bullosa (arrow) with ipsilateral osteomeatal unit block in a subject of case group. 


\section{ORIGINAL ARTICLE}

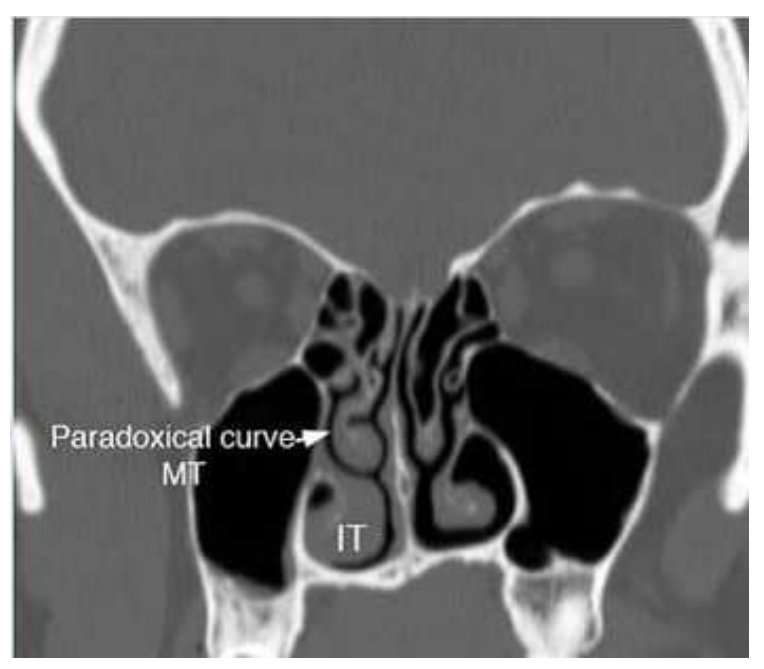

Figure 3: coronal ct image showing paradoxical turn of rt middle turbinates (arrow) in a subject of control (normal) group. (it: inferior turbinate)

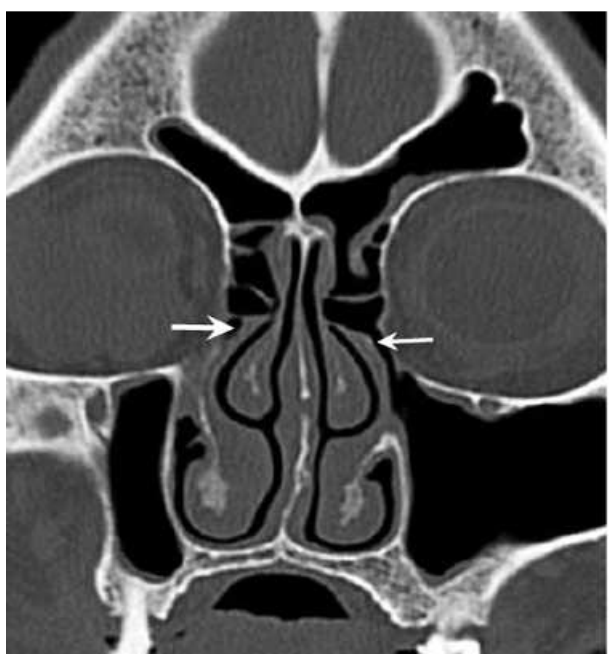

Figure 4: coronal ct showing retroverted bilateral uncinate process (arrows) in a subject of control (normal) group.

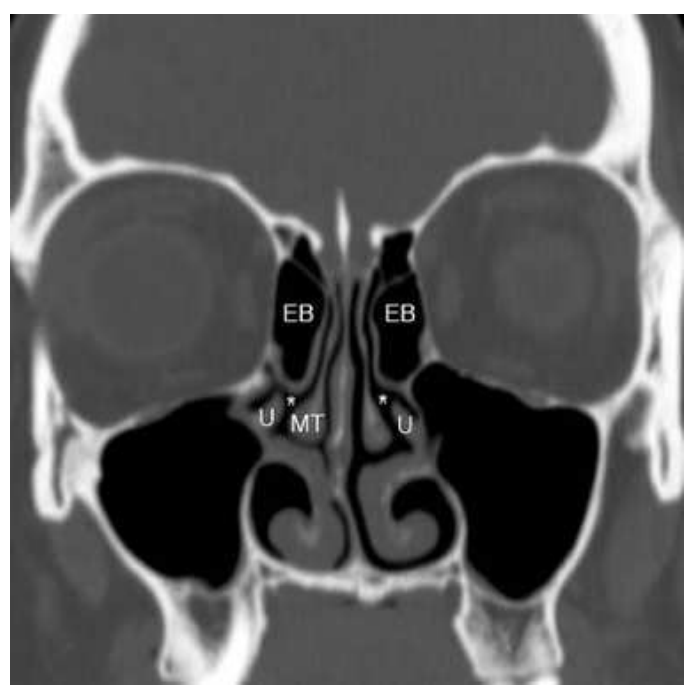

Figure 5: coronal ct image showing haller cell (infraorbital air cells) in a subject of control (normal) group. [mt-middle turbinate, ms-maxillary sinus]

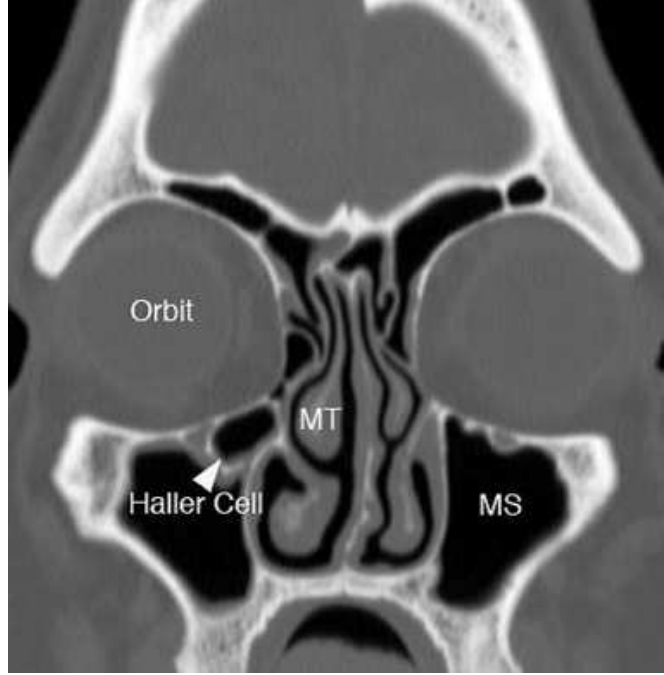

Figure 6: coronal ct image showing bilateral overpneumatized ethmoidal bullae (eb) in a subject of control (normal) group. [u: uncinate process, mt: middle turbinate] 


\section{ORIGINAL ARTICLE}

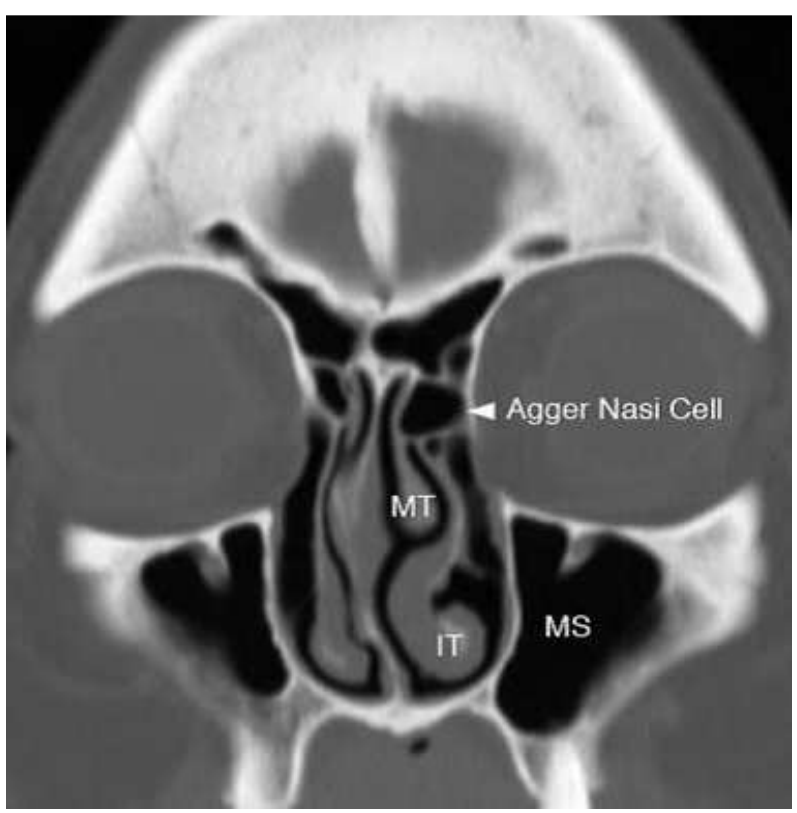

Figure 7: coronal ct image showing agger nasi cell in a subject of control (normal) group. [mt-middle turbinate, it-inferior turbinate, ms-maxillary sinus]

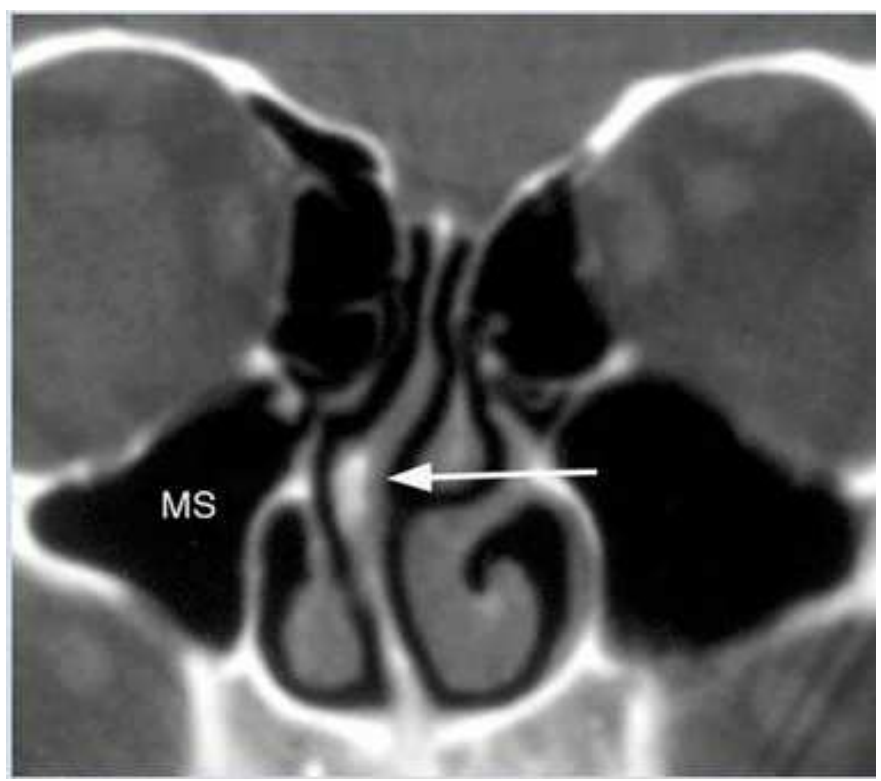

Figure 8: coronal ct scan showing septal deviation towards right (arrow) in a subject of control (normal) group. (ms: maxillary sinus) 